\title{
Synchrotron microtomographic quantification of geometrical soil pore characteristics affected by compaction
}

\author{
Ranjith P. Udawatta ${ }^{1,2}$, Clark J. Gantzer ${ }^{1}$, Stephen H. Anderson ${ }^{1}$, and Shmuel Assouline ${ }^{3}$ \\ ${ }^{1}$ Dept. of Soil, Environmental and Atmospheric Sciences, School of Natural Resources, University of Missouri, \\ Columbia, MO 65211, USA \\ ${ }^{2}$ The Center for Agroforestry, School of Natural Resources, University of Missouri, \\ Columbia, MO 65211, USA \\ ${ }^{3}$ Dept. of Environmental Physics and Irrigation, Agricultural Research Organization, Volcani Center, \\ Bet-Dagan, Israel \\ Correspondence to: Ranjith P. Udawatta (udawattar@missouri.edu)
}

Received: 26 June 2015 - Published in SOIL Discuss.: 31 July 2015

Revised: 14 April 2016 - Accepted: 24 April 2016 - Published: 19 May 2016

\begin{abstract}
Soil compaction degrades soil structure and affects water, heat, and gas exchange as well as root penetration and crop production. The objective of this study was to use X-ray computed microtomography (CMT) techniques to compare differences in geometrical soil pore parameters as influenced by compaction of two different aggregate size classes. Sieved (diameter $<2 \mathrm{~mm}$ and $<0.5 \mathrm{~mm}$ ) and repacked $\left(1.51\right.$ and $1.72 \mathrm{Mg} \mathrm{m}^{-3}$ ) Hamra soil cores of 5 by $5 \mathrm{~mm}$ (average porosities were 0.44 and 0.35 ) were imaged at $9.6 \mu \mathrm{m}$ resolution at the Argonne Advanced Photon Source (synchrotron facility) using X-ray CMT. Images of $58.9 \mathrm{~mm}^{3}$ volume were analyzed using 3-Dimensional Medial Axis (3-DMA) software. Geometrical characteristics of the spatial distributions of pore structures (pore radii, volume, connectivity, path length, and tortuosity) were numerically investigated. Results show that the coordination number $(\mathrm{CN})$ distribution and path length (PL) measured from the medial axis were reasonably fit by exponential relationships $\mathrm{P}(\mathrm{CN})=10^{-\mathrm{CN} / \mathrm{Co}}$ and $\mathrm{P}(\mathrm{PL})=10^{-\mathrm{PL} / \mathrm{PLo}}$, respectively, where Co and PLo are the corresponding characteristic constants. Compaction reduced porosity, average pore size, number of pores, and characteristic constants. The average pore radii (63.7 and $61 \mu \mathrm{m} ; p<0.04)$, largest pore volume $\left(1.58\right.$ and $\left.0.58 \mathrm{~mm}^{3} ; p=0.06\right)$, number of pores (55 and $\left.50 ; p=0.09\right)$, and characteristic coordination number $(3.74$ and $3.94 ; p=0.02)$ were significantly different between the low-density than the high-density treatment. Aggregate size also influenced measured geometrical pore parameters. This analytical technique provides a tool for assessing changes in soil pores that affect hydraulic properties and thereby provides information to assist in assessment of soil management systems.
\end{abstract}

1

Degradation of soil structure is a serious worldwide problem (Shrader et al., 2007). Soil structure is important for crop production because it partly determines rooting depth; the amount of water that can be stored; and movement of air, water, nutrients, and soil microfauna (Brussaard and van Faassen, 1994; Whalley et al., 1995). During soil compaction, soil structure is degraded and soil aggregates are consolidated decreasing soil porosity, and subsequently these changes alter water, heat, and gas transport as well as root penetration and soil productivity (Assouline, 2002; Kim et al., 2010). Assessment of soil compaction is a fundamental way to evaluate environmental impacts of agricultural operations on soils.

Researchers have been evaluating soil compaction due to natural and anthropogenic activities (Soane and van Ouwerkerk, 1995; Assouline et al., 1997; Marsili et al., 1998; 
Green et al., 2003). Differences in porosity among dissimilar soils and treatments are often quantified using bulk density estimated with soil cores, changes in soil thickness, and changes in penetrometer resistance. Porosity determined by traditional methods often lacks detailed information on spatial variability in geometrical pore characteristics. In addition, porosity is often estimated by indirect procedures which do not contain information on the spatial distribution of pores and most measurements are based on observations in two dimensions (Beven and Germann, 1982; Gantzer and Anderson, 2002; Mooney, 2002).

Soil scientists are working to examine the microstructure of the soil system to better predict water and gas movement, to assess the effects of management on soil pore parameters and microbial habitats, and to evaluate treatment effects on root development. Microstructure governs the flow of resources through the pore space of the soil media and creates spatial and temporal differences in the media (Young and Crawford, 2004; Zhang et al., 2005). Research suggests that understanding of geometrical pore parameters is critically important to issues related to the movement of microfauna, water, solutes, and gases, as well as root development. These pore parameters include pore dimension, pore size distribution, connectivity, shape factor, and tortuosity as well as distributions or probabilities of these parameters (Ioannidis and Chatzis, 1993, 2000; Tollner et al., 1995; Lindquist et al., 2000).

Computed microtomography (CMT) can be viewed as a technique in soil studies that enables examination of local variation (micrometer scale), whereas conventional tomography enables examination at a millimeter scale (Macedo et al., 1998). Computed microtomography has been used in examination of pores in sealing materials for nuclear waste and in rock and soil media as well as evaluation of fluid transport; in addition, pore dynamics and bacterial and root studies have been reported (Coles et al., 1998; Kozaki et al., 2001; Lindquist, 2002; Gregory et al., 2003; Thieme et al., 2003; Udawatta et al., 2008; Peth et al., 2010). However, these procedures require images at micrometer resolution to accurately describe changes within the media. Better resolution in tomography requires a smaller sample size. Advantages of CMT procedures include repeated examination of interior structural features of samples at micrometer-scale resolution within three dimensions, measurement of connectivity and tortuosity, nondestructive evaluation of sample interiors retaining connectivity and spatial variation in pores, and enabling examination of dynamic soil processes and quantification of pore geometry (Asseng et al., 2000; Al-Raoush, 2002; Mooney, 2002; Pierret et al., 2002; Carlson et al., 2003; Udawatta et al., 2008).

Quantitative information of soil structure is required to improve understanding of infiltration, contaminant movement through porous media, and quantification of model parameters associated with fluid and gas movement (Pachepsky et al., 1996; Perret et al., 1999; Ioannidis and Chatzis,
2000; Wildenschild et al., 2002; Fox et al., 2004; Assouline, 2004). However, CMT, volume rendering, and threedimensional (3-D) image analysis studies focusing on soil compaction are rare. The objective of this study was to use synchrotron X-ray computed microtomography to quantify the influence of mechanical compaction on geometrical soil pore characteristics of two soil aggregate classes.

\section{Materials and methods}

\subsection{Soil and sample preparation}

The soil used for this study was a loamy sand (Typic Rhodoxeralf) collected from the $0-100 \mathrm{~mm}$ depth of an experimental field at Bet-Dagan, Central Israel $\left(32^{\circ} 12^{\prime} \mathrm{N}, 35^{\circ} 25^{\prime} \mathrm{E}\right)$. The soil contains $87 \%$ sand, $2 \%$ silt, and $11 \%$ clay (mainly smectite). Air-dried soil was sieved through 2.0 and $0.5 \mathrm{~mm}$ mesh sieves to separate into two aggregate size classes: $<2$ and $<0.5 \mathrm{~mm}$. Soil was packed in $5 \mathrm{~mm}$ long by $5 \mathrm{~mm}$ diameter aluminum cores with $1.0 \mathrm{~mm}$ wall thickness, in three replicates for each treatment. Soil cores from each aggregate class were compacted with a small press to obtain pre-determined bulk density values of 1.51 and $1.72 \mathrm{Mg} \mathrm{m}^{-3}$. The selected two values represent the range in bulk densities commonly found with these soils and site conditions. The open ends of the soil core were covered with aluminum plates and sealed with tape to secure soil materials inside the core. Samples were stored at room temperature before scanning.

\subsection{Image acquisition and tomographic reconstruction}

Air-dried soil cores were transported to the GeoSoilEnviroCARS (GSECARS) sector at the Argonne Advanced Photon Source for image acquisition at the X-ray computed microtomography facility (https://gsecars.uchicago.edu/). Soil cores were imaged at a $9.6 \mu \mathrm{m}$ resolution using the bending magnet beam line 13-BM-D, which provides a parallel beam of highbrilliance radiation with a vertical beam size of about $5 \mathrm{~mm}$. Specific synchrotron tomographic procedures and additional details can be found in Kinney and Nichols (1992).

The data processing consisted of three main steps: preprocessing, sinogram creation, and reconstruction. Since there is a constant digitization offset ( $\sim 50$ counts), this value was subtracted from each pixel. The second step was to remove "zingers"; these are bright pixels caused by scattered X-rays striking the CCD chip. The third step of the preprocessing was completed to normalize each data frame to the field image and to correct for drift.

The first step of sinogram creation was to take the logarithm of the data relative to air. Centering the rotation axis of the projection was completed by fitting a sinusoid to the center of gravity of each row in the sinogram. Ring artifacts were removed by detecting and correcting anomalous columns in the sinogram. Tomographic reconstruction was completed using filtered back projection with the IDL pro- 
gramming language (Rivers, 1998). The raw data used for tomographic reconstruction were 12 bit images with a total of 360 images collected as the sample was rotated twice from 0 to $180^{\circ}$ in $0.5^{\circ}$ steps. The data were piped to massively parallel SGI computers to view real-time data before image acquisition was completed.

\subsection{Image analysis}

The 3-Dimensional Medial Axis (3-DMA) computer software was used to examine differences in geometrical pore characteristics among the treatments (Lindquist, 1999; Lindquist and Venkatarangan, 1999) using a $1.7 \mathrm{GHz}$ Linux computer with $2 \mathrm{~GB}$ of memory. Pore characteristics were analyzed at $9.2 \times 10^{2} \mu \mathrm{m}^{3}$ voxel size $(1 \mathrm{pixel}=9.61 \mu \mathrm{m}$ and 1 slice $=10 \mu \mathrm{m}$; voxel size $=9.61 \times 9.61 \times 10$ ). Images were cropped into a 3.7 by 3.7 by $4.3 \mathrm{~mm}$ rectangular array block to remove artifacts. Spatial distributions for nodal pore volume, coordination numbers, pore path length, and tortuosity were obtained for $58.9 \mathrm{~mm}^{3}$ volumes. The six main analysis steps in 3-DMA were completed by a number of imbedded algorithms: segmentation of image, extraction and modification of the medial axis of pore paths, throat construction using the medial axis, pore surface construction, assembly of pore throat network, and geometrical characterization of pore throat network (http://www.ams.sunysb.edu/ lindquis/3dma/ 3dma_rock/3dma_rock.html, last access: June 2015).

The greyscale intensity of each CT-image voxel is an integer value from 0 to 255 ( $2^{8}$ bit scale). Simple thresholding and indicator kriging (IK; Oh and Lindquist, 1999) separated the voxels into two populations using intensity values and voxels having intermediate intensities by using the maximum likelihood estimate of the population set, respectively (Fig. 1). Indicator kriging requires subpopulations of voxels for each phase (pore and solid) to be positively identified. The remaining voxels were assigned by the IK algorithm according to neighborhood statistics. This was satisfied by using greyscale intensity values for air and aluminum as threshold cutoff values. These two thresholds were set manually on histograms to separate populations.

The medial axis of a sample is a centrally located skeleton of voids which preserves the topology and geometry of the object (Sirjani and Cross, 1991). An erosion-based algorithm is used to extract and modify the medial axis of the pore space (Lee et al., 1994). Spurious paths, which are not significant descriptors of the object, and all dead-end paths were removed (trimmed) from the volume. A filter was used to minimize misidentification of segmentation artifacts such as small isolated pores/clusters. The process resulted in the medial axis "backbone".

The 3-DMA software uses throat-finding algorithms (Venkatarangan, 2000; Shin et al., 2002) to determine the location of minimal-area cross-sectional surfaces where one or more void paths pass, called pore throats (Kwiecien et al., 1990). The throat region is defined by the voxel sets through

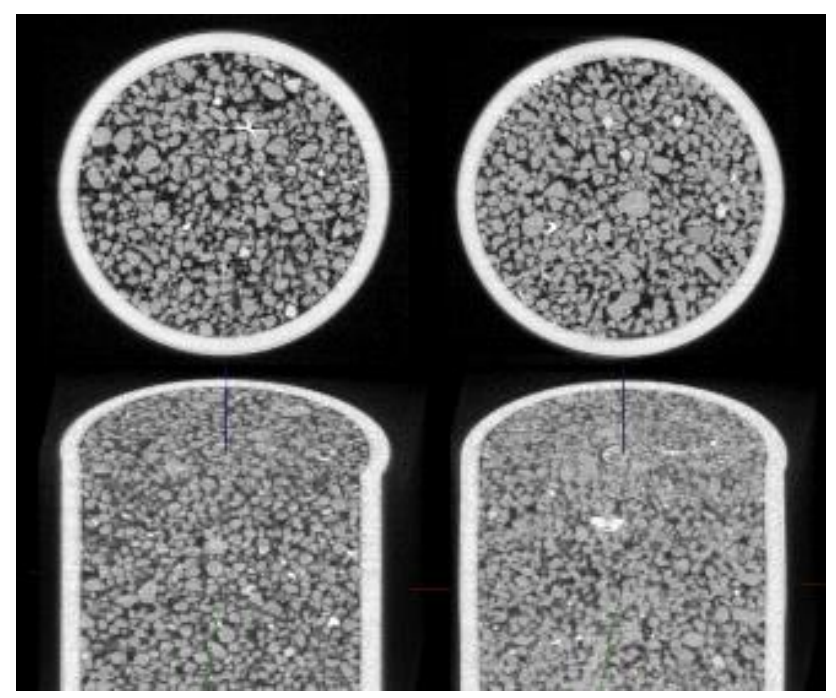

Figure 1. Cross-sectional and three-dimensional images of soil core samples for bulk density $1.51 \mathrm{Mg} \mathrm{m}^{-3}$ (left panel) and $1.72 \mathrm{Mg} \mathrm{m}^{-3}$ (right panel).

which each triangulated throat surface pass, and throat surface areas are determined as triangulated interfaces.

The next step is to determine the network of pore paths (a connected curve of voxels) and vertices (a cluster of one or more voxels where three or more paths intersect). Throat surfaces separate pore spaces and determine network of pores. Pores are cross-indexed with their connecting throats and adjoining pores, while throats are cross-indexed with the pores they connect. The algorithm also computes a center of mass, principal directions for each pore, and the diameter passing through the center of mass in each principal direction. An effective pore radius can be computed using the sphere of equivalent volume. The analysis generated distributions of the principal diameters and the effective radius values for the pores and throats.

Path length (the distance between the centers of any two adjacent nodal pores along the midline of the connecting path) is determined by the distance measure algorithm (Lindquist, 2002). Dijkstra's algorithm (Cormen et al., 1990) embedded as part of the 3-DMA software determined path tortuosity. The algorithm uses a gamma distribution for tortuosity probability distribution (Lindquist et al., 1996) and generated tortuosity of each pore as well as average and cumulative tortuosity values for each sample. The software generated an assembly of pore networks and geometrical characteristics of pore networks. The following information generated by the 3-DMA was analyzed as outlined in Lindquist et al. (2005): effective radius, pore volume, coordination number, path length, and path tortuosity along with their corresponding probability density relationships.

The coordination number $(\mathrm{CN})$ is measured by directly counting the distribution of medial axis vertex sets. Coor- 
dination numbers between 3 and 20 were used to develop exponential distribution relationships $\left[\mathrm{P}(\mathrm{CN})=10^{-\mathrm{CN} / \mathrm{Co}}\right]$ between coordination numbers and probability density values to determine characteristic coordination number constants (Co) for each sample. A similar approach was used to determine characteristic path length constants (PLo), fitting an exponential distribution $\left[\mathrm{P}(\mathrm{PL})=10^{-\mathrm{PL} / \mathrm{PLo}}\right]$ of path length (PL) and probability density. Pore radii $(\mu \mathrm{m})$, pore volume $\left(\mathrm{mm}^{3}\right)$, coordination number, path length, and tortuosity differences were compared among treatments. A selected replicate for each treatment was used to show the distributions of above properties in figures.

\subsection{Statistical analysis}

Geometrically determined pore parameters were analyzed to examine differences and similarities among treatments for pore radius, volume, porosity, mean pore volume, number of pores, coordination number, path length, and tortuosity as described by Lindquist et al. (2000). Bulk-averaged variables have become the "historical operational descriptors" in theoretical description of porous media microstructure. Therefore, the averaged values are given in Table 1. Four treatments in factorial design (two factors of density and aggregate size; two levels) were compared: two aggregate size classes $(<2.0$ and $<0.5 \mathrm{~mm}$ diameter referred to as $\mathrm{H} 2$ and H5, respectively) and two compaction levels identified as low (L) and high $(\mathrm{H})$ representing two bulk density values (1.51 and $1.72 \mathrm{Mg} \mathrm{m}^{-3}$, respectively) with three replicates. Analysis of variance was conducted with SAS using the GLM procedure to test differences between treatments (SAS Institute, 1985). Least-squares means were calculated to find significant differences between treatments for each measured parameter. Statistical tests included normality of data distribution and significant differences among treatments.

\section{Results and discussion}

\subsection{Effective pore radii and volume}

Since effective pore radii were not normally distributed, log-transformed effective pore radii values were used in the statistical analysis. Effective pore radii were 63.75 and $61.18 \mu \mathrm{m}$ for 1.51 and $1.72 \mathrm{Mg} \mathrm{m}^{-3}$ treatments (averaged for both aggregate sizes), respectively (Table 1, Fig. 2), and the compaction was significant $(p=0.04)$. As expected, pore radius decreased with increasing density. However, aggregate particle size had no significant effect on measured pore radii. Mean pore radii were 62.64 and $62.29 \mu \mathrm{m}$ for 0.5 and $2.0 \mathrm{~mm}$ aggregate sizes (averaged for both densities), respectively.

Similar to effective pore-radii, log-transformed pore volumes were used for analysis. Table 1 shows that total pore volume, largest pore size, mean pore volume, and number of pores decreased with increasing compaction for the high-density samples compared to low density. The largest
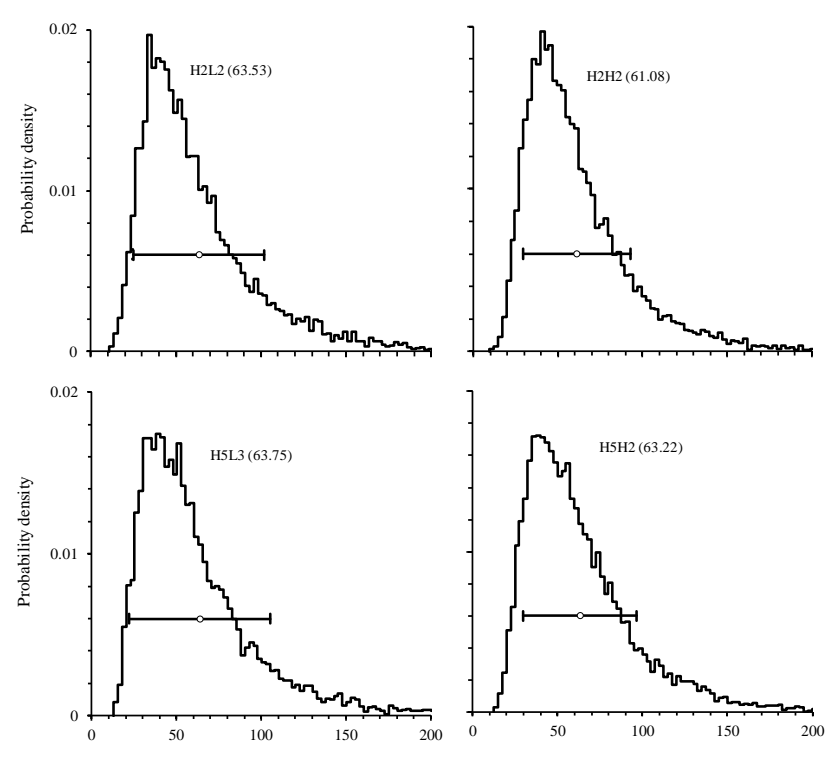

Effective pore radii, $\mu \mathrm{m}$

Effective pore radii, $\mu \mathrm{m}$

Figure 2. Probability density distributions versus pore radii for Hamra 2.0 and $0.5 \mathrm{~mm}$ aggregate treatments (H2 and H5) and lowand high-compaction treatments (L and $\mathrm{H})$. Selected replicates are shown in the figure (last number in treatment name is replicate). The number within parentheses is the sample mean pore radius in micrometers. The circle represents the average pore radii and the horizontal line indicates the standard deviation of the mean.

pore volume and number of pores were different $(p<0.10$, Fig. 3). However, the largest pore size was 2.7 times larger in the less compacted treatment as compared to the highdensity treatment. The average pore volumes were $7.1 \times 10^{5}$ and $6.6 \times 10^{5} \mu^{3}$ for 1.51 and $1.72 \mathrm{Mg} \mathrm{m}^{-3}$ bulk density treatments (averaged for both aggregate sizes), respectively. CMT-measured porosity values were 10.9 and $4.9 \%$ for the high- and low-density treatments, respectively. Note that the CMT-measured porosity is lower than the core-estimated porosity due to the limited resolution of the scanner. Total core porosity was 1.2 times smaller and CMT-measured pore volume was 2.2 times smaller in the high-density treatment as compared to the low-density treatment. This result is consistent with the fact that the soil porosity should decrease when moving from low to high bulk density, although the range in values will be smaller for the bulk core properties. The aggregate size class containing finer aggregates (H5) had 1.7 times more pore volume, 2.1 times greater largest pore volume, and more pores than the aggregate class including larger aggregates (H2). In terms of the effect of compaction on pore size distribution, Figs. 1 and 2 show that compaction preferentially affected the larger pores, reducing them in size (radius and volume) in both aggregate categories. This is in agreement with the estimated effect of compaction on the pore size distribution derived from changes in the water retention curve (Assouline, 2006a). 

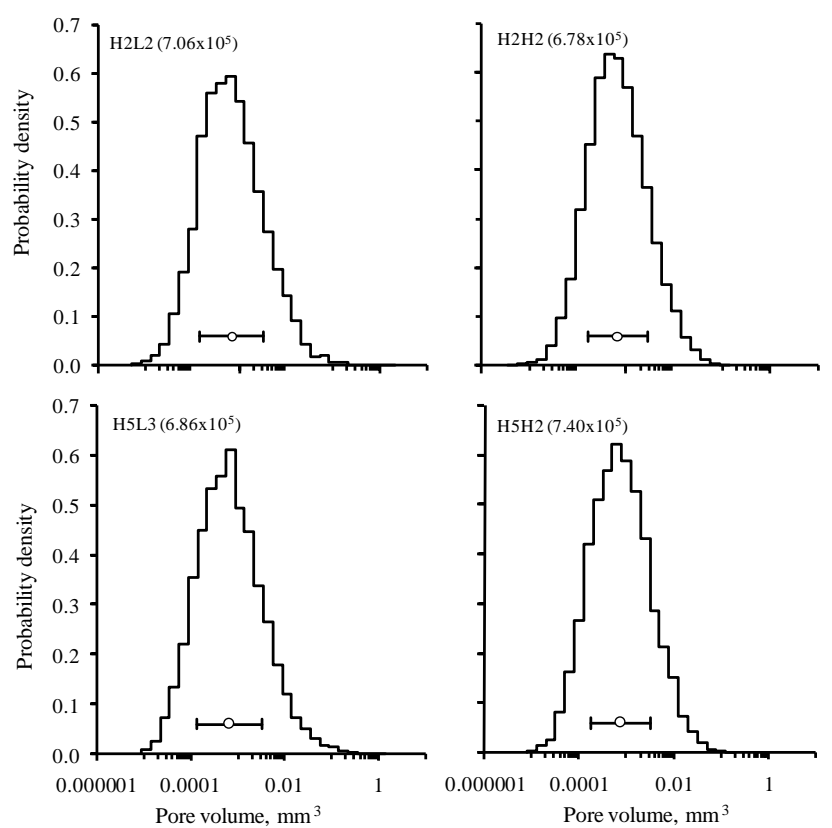

Figure 3. Probability density distributions versus pore volume for Hamra 2.0 and $0.5 \mathrm{~mm}$ aggregate treatments (H2 and $\mathrm{H} 5)$ and lowand high-compaction treatments ( $\mathrm{L}$ and $\mathrm{H})$. Selected replicates are shown in the figure (last number in treatment name is replicate). The number within parentheses is the sample mean pore volume in cubic micrometers. The circle represents the average pore volume and the horizontal line indicates the standard deviation of the mean.

The results observed in this study agree with findings between soil porosity and pore size distribution relationships in previously published data (Lindquist et al., 2000; Seright et al., 2001; Udawatta et al., 2008). Although differences in pore volume and radii may exist among treatments, the effects may be somewhat less dominant due to fewer aggregates (due to sandy texture) and/or few inter-aggregate spaces (due to sandy texture).

\subsection{Coordination number}

Higher pore coordination numbers $(\mathrm{CN})$ imply greater connectivity developing between nodal pore sites that are well connected and extended, i.e., a good pore network. Coordination numbers varied between 3 and 40 and $\leq 20$ were used to develop relationships (Fig. 4). Coefficients of determination for the $\mathrm{CN}$ and probability relationships were $>0.99$ for all treatments. The coordination number constant $(\mathrm{Co})$ values varied between 3.44 and 4.29 with a mean of $3.91 \pm 0.27$ for all samples. Coordination number constants was significantly different between low- and high-density treatments (Table 1; $p<0.02$ ). The low-density treatment had $6 \%$ greater probability for pore connectivity than the high-density treatment. The same trend was observed for both aggregate categories of low-density treatments as compared to the high-density treatment (Table 1). The mean Co values were 3.72 and 3.97

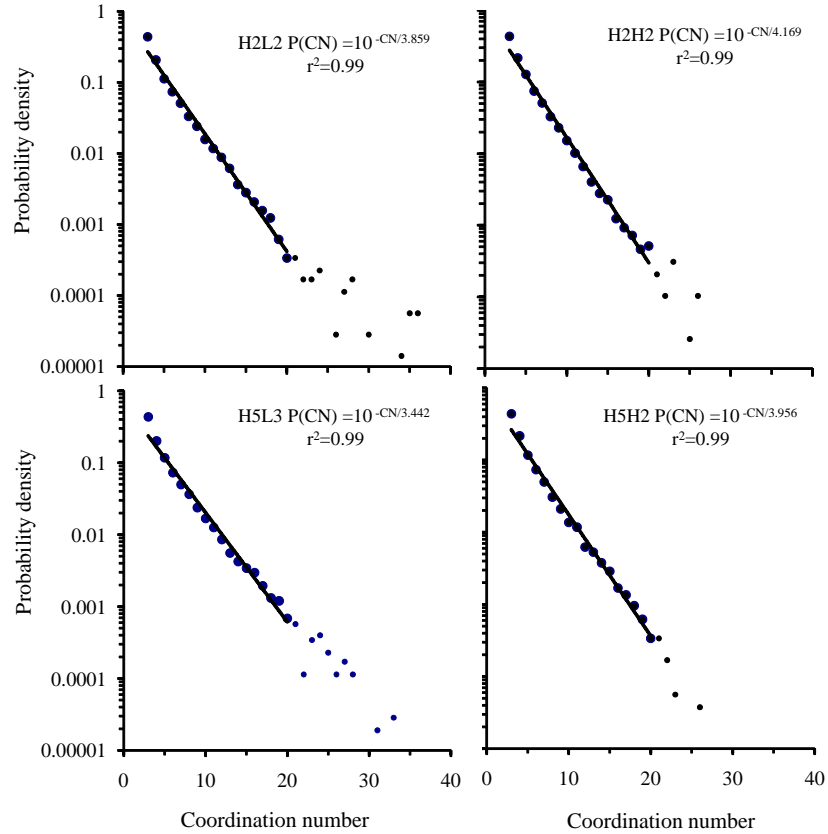

Figure 4. Probability density distributions versus coordination number for Hamra 2.0 and $0.5 \mathrm{~mm}$ aggregate treatments $(\mathrm{H} 2$ and H5) and low- and high-compaction treatments ( $\mathrm{L}$ and H). Selected replicates are shown in the figure (last number in treatment name is replicate). Coordination number $(\mathrm{CN})$ is the number of curve segments meeting at the vertex and $\mathrm{Co}$ is the characteristic coordination number constant, which is the value in each equation.

for 0.5 and $2.0 \mathrm{~mm}$ diameter aggregate treatments, respectively $(p<0.10)$.

The range of Co values observed in this study were similar compared to values observed for heterogeneous soil material (Udawatta et al., 2008). In Udawatta et al. (2008), larger soil cores were analyzed at $84 \mu \mathrm{m}$ resolution and Co values ranged between 3.30 and 5.14. The selected 3 to 20 coordination number range for the current study resulted in a straight line as compared to the ranges used by Lindquist et al. (2000) and Udawatta et al. (2008) in their relationships. Lindquist et al. (2000) imaged rock material at $6 \mu \mathrm{m}$ resolution, as compared to $9.6 \mu \mathrm{m}$ resolution in this study. Both Lindquist et al. (2000) and Udawatta et al. (2008) reported significant differences in Co values among treatments. We speculate that soil material with more uniform size particles and lack of aggregates may have caused small differences among treatments. In addition, treatments examined in this study further segregated soil particles by creating aggregate size classes as a treatment and thereby forming more homogeneous samples. This also suggests that these soils with more uniform larger grain size lose more pore connectivity than small particles during compaction. Results may indicate that the rate of air and liquid flow may be reduced by compaction due to a lower number of connected pores. Another reason for the observed Co values could be that compaction preferentially 
Table 1. Geometrical pore parameters (pore radius, pore volume, number of pores, characteristic coordination number, characteristic path length, and tortuosity) as influenced by aggregate size and compaction treatments and ANOVA. Soil cores were scanned at the GeoSoilEnviroCARS (GSECARS) sector at the Argonne Advanced Photon Source X-ray computed microtomography facility. Bold numbers denote significant differences at the 0.05 level.

\begin{tabular}{|c|c|c|c|c|}
\hline Treatment & $\begin{array}{l}\text { Mean } \\
\text { pore } \\
\text { radius, } \\
\mu \mathrm{m}\end{array}$ & $\begin{array}{l}\text { Total } \\
\text { pore } \\
\text { volume, } \\
\mathrm{mm}^{3}\end{array}$ & $\begin{array}{l}\text { Largest } \\
\text { pore } \\
\text { volume, } \\
\mathrm{mm}^{3}\end{array}$ & $\begin{array}{l}\text { Mean } \\
\text { pore } \\
\text { volume, } \\
\mu \mathrm{m}^{3}\end{array}$ \\
\hline \multicolumn{5}{|c|}{ Aggregate treatment means } \\
\hline $0.5 \mathrm{~mm}$ & 62.64 & 5.87 & 1.47 & $6.8 \times 10^{5}$ \\
\hline $2.0 \mathrm{~mm}$ & 62.29 & 3.45 & 0.69 & $6.9 \times 10^{5}$ \\
\hline \multicolumn{5}{|c|}{ Compaction treatment means } \\
\hline $1.51 \mathrm{Mg} \mathrm{m}^{-3}$ & 63.75 & 6.45 & 1.58 & $7.1 \times 10^{5}$ \\
\hline $1.72 \mathrm{Mg} \mathrm{m}^{-3}$ & 61.18 & 2.87 & 0.58 & $6.6 \times 10^{5}$ \\
\hline Average & 62.46 & 4.66 & 1.08 & $6.6 \times 10^{5}$ \\
\hline Standard error & 0.76 & 1.86 & 0.33 & $2.6 \times 10^{5}$ \\
\hline \multicolumn{5}{|c|}{ Analysis of variance } \\
\hline Treatment & 0.183 & 0.478 & 0.129 & 0.640 \\
\hline Aggregate (0.5 vs. $2.0 \mathrm{~mm})$ & 0.753 & 0.384 & 0.127 & 0.790 \\
\hline Compaction (1.51 vs. $\left.1.72 \mathrm{Mg} \mathrm{m}^{-3}\right)$ & 0.044 & 0.212 & 0.063 & 0.286 \\
\hline Aggregate $\cdot$ compaction & 0.533 & 0.852 & 0.773 & 0.556 \\
\hline Treatment & $\begin{array}{l}\text { Number } \\
\text { of } \\
\text { pores }\end{array}$ & $\begin{array}{l}\text { Characteristic } \\
\text { coordination } \\
\text { number }(\mathrm{Co})\end{array}$ & $\begin{array}{l}\text { Characteristic } \\
\text { path length } \\
\text { number (PLo) }\end{array}$ & Tortuosity \\
\hline \multicolumn{5}{|c|}{ Aggregate treatment means } \\
\hline $0.5 \mathrm{~mm}$ & 54 & 3.72 & 185 & 1.21 \\
\hline $2.0 \mathrm{~mm}$ & 50 & 3.97 & 174 & 1.20 \\
\hline \multicolumn{5}{|c|}{ Compaction treatment means } \\
\hline $1.51 \mathrm{Mg} \mathrm{m}^{-3}$ & 55 & 3.74 & 179 & 1.20 \\
\hline $1.72 \mathrm{Mg} \mathrm{m}^{-3}$ & 50 & 3.94 & 180 & 1.21 \\
\hline Average & 52 & 3.84 & 179 & 1.20 \\
\hline Standard error & 1.8 & 0.05 & 7.7 & 0.004 \\
\hline \multicolumn{5}{|c|}{ Analysis of variance } \\
\hline Treatment & 0.184 & 0.007 & 0.654 & 0.341 \\
\hline Aggregate (0.5 vs. $2.0 \mathrm{~mm})$ & 0.193 & 0.010 & 0.390 & 0.134 \\
\hline Compaction ( 1.51 vs. $1.72 \mathrm{Mg} \mathrm{m}^{-3}$ ) & 0.089 & 0.029 & 0.901 & 0.346 \\
\hline Aggregate $\cdot$ compaction & 0.537 & 0.025 & 0.372 & 0.747 \\
\hline
\end{tabular}

affected larger pores reducing them in size, while smaller pores maintained the same connectivity (Figs. 1-3). This pattern has been observed by soil water retention studies as influenced by compaction (Or et al., 2000; Assouline, 2006b; Kumar et al., 2008).

\subsection{Path length}

Path lengths (PL) measured in this study ranged from 3 to $597 \mu \mathrm{m}$ (Fig. 5). Path lengths between 100 and $400 \mu \mathrm{m}$ were selected for the development of exponential relationships $\left[\mathrm{P}(\mathrm{PL}) \sim 10^{-\mathrm{PL} / \mathrm{PLo}}\right]$ between path length and probability density. The selected range exhibited a linear relationship with coefficients of determination ranging from 0.96 to 0.98 with a mean of 0.97 . Characteristic path length 

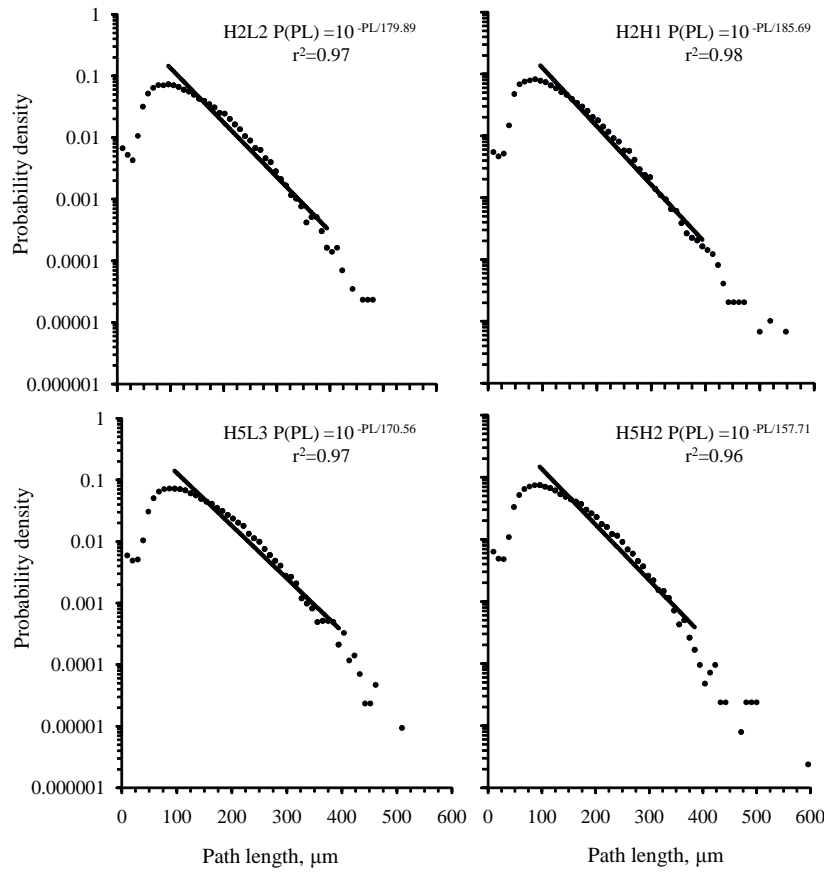

Figure 5. Probability density distributions versus pore path length for Hamra 2.0 and $0.5 \mathrm{~mm}$ aggregate treatments (H2 and $\mathrm{H} 5)$ and low- and high-compaction treatments $(\mathrm{L}$ and $\mathrm{H})$. Selected replicates are shown in the figure (last number in treatment name is replicate). Path length (PL) is the length of the path between adjacent connected nodal pores and PLo is the characteristic path length constant, which is the value in each equation.

constants (PLo) ranged from 157.7 to 219.3 with a mean of 179.5. Mean PLo values for the low- and high-density treatments were 179 and 180 , respectively, and the difference was not significant (Table 1). The greater PLo values imply a greater probability of occurrence of a given path length than in the high-density treatment. Between the two aggregate size classes, $0.5 \mathrm{~mm}$ aggregates had a larger PLo (185) as compared to the larger aggregates (174; not significantly different). This high PLo is an indication of greater probability of paths in a soil with small aggregates.

Researchers have used differences in path lengths imaged by varying resolutions to compare porosity in sandstone and conservation management effects on path lengths. Lindquist et al. (2000) observed differences in PLo values in sandstone with porosities varying from 7 to $22 \%$. Udawatta et al. (2008) showed that PLo was significantly higher for buffer treatments as compared to row-crop management. According to Wu et al. (2006), path length was higher for smaller particles. The greater path lengths in smaller particle media have been attributed to larger pore spaces among larger particles that reduced the distance due to relatively easier corners in the media. They also noticed that relative path lengths were higher through pores as compared to over the grains in their
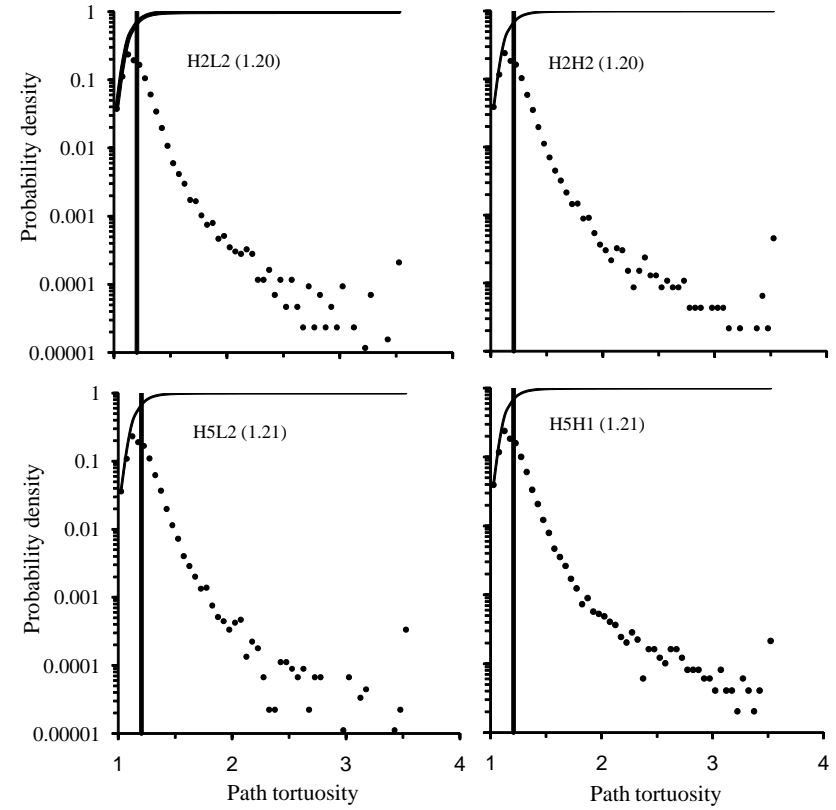

Figure 6. Probability density (solid points) versus path tortuosity and cumulative probability density (solid line) versus path tortuosity for Hamra 0.5 and $2.0 \mathrm{~mm}$ aggregate treatments ( $\mathrm{H} 0.5$ and $\mathrm{H} 2.0$ ) and low- and high-compaction treatments ( $\mathrm{L}$ and H). Selected replicates are shown in the figure (last number in treatment name is replicate). The vertical line and the number within parentheses is the sample mean tortuosity.

scanning electron microscope study with cubic sodium chloride.

\subsection{Path tortuosity}

Figure 6 shows that probability decreased with increasing path tortuosity and tortuosity values ranged from 1 to 3.7. The highest probability occurred at a path tortuosity of 1.12 . In general, the probability was less than $0.05 \%$ for path tortuosity values greater than 2 and the distribution of data points was more scattered for tortuosity values $>2.5$.

Although tortuosity of the pore network depends on the grains in the media (Friedman and Robinson, 2002), the aggregate treatment was not significant in the current study $(p=0.13$; Table 1$)$. Slightly greater tortuosity for smaller particles could be due to image analysis techniques as larger particles create larger spaces between particles, thus reducing the tortuousness of paths. In contrast, tortuosity increased linearly with increasing particle size and the gas diffusion coefficient decreased in a plant growth media study with 1 to $16 \mathrm{~mm}$ size bark materials (Knongolo and Caron, 2006). Higher tortuosity values due to compaction, aggregate size, or management affect water, solute, and gas movement through the media, and higher tortuosity imposes greater resistance. 
Mean tortuosity values were 1.20 and 1.21 for 1.51 and $1.72 \mathrm{Mg} \mathrm{m}^{-3}$ bulk density treatments, respectively (Table 1). Pore paths were $0.8 \%$ more tortuous for the higher compaction as compared to the lower compaction (not significantly different). In addition, the probability was slightly higher for tortuosity $>2.5$ for more compacted soils than the $1.51 \mathrm{~g} \mathrm{~cm}^{-3}$ bulk density soil.

Average tortuosity values between 1.46 and 1.74 were observed among crop and buffer soils (Udawatta et al., 2008). The mean tortuosity value was 2.7 with a 1.5 to 4.5 range in a fluid transport study, using synchrotron CMT (Coles et al., 1998). Path tortuosity values observed in this study and the Udawatta et al. (2008) were less than 1.75, while Perret et al. (1999) observed values as high as 2.4. The difference can be attributed to image resolution and image analysis software.

Imaging techniques are capable of estimating tortuosity in the $x, y$, and $z$ directions (Wu et al., 2006). Such measurements are important for materials with anisotropic pore structure that have preferential pore directions. For example, clay soils with restrictive horizons may promote lateral flow above the restrictive horizons. In contrast, compaction may occur in three dimensions and pore structure may not always form a continuous network creating isolated pores. At this time, it is not clear whether tortuosity data measured in all cardinal directions and locations will be useful in predicting transport. Future studies are needed to examine how water, solute, and gas movement are affected by anisotropic tortuosity among porous media with heterogeneous particles.

\subsection{Pore characteristics of (Co) and (PLo) as influenced by aggregate size and compaction}

Conventional methods for determination of porosity document that aggregate size and compaction significantly decrease pore size. Our results show that these changes are relatively small making it difficult to discriminate among soils of differing aggregate size and compaction.

Using CMT methods, determination of the network of pore paths (Co) and the path length of pores (PLo) is possible. Results show much greater change in these characteristics compared to pore size. Change in Co from 2 to $0.5 \mathrm{~mm}$ aggregates averaged over density reduced the connections by $4 \%$, while change in Co from 1.51 to $1.72 \mathrm{Mg} \mathrm{m}^{-3}$ reduced the pores' connections by $6.4 \%$, a much greater reduction than the reduction in pore radius. Values for PLo reflecting the tortuous nature of path lengths show the greatest discrimination among the aggregate size and compaction treatments. Not surprisingly, change in PLo from 2 to $0.5 \mathrm{~mm}$ aggregates averaged over density increased path tortuosity by $4.3 \%$ as smaller aggregates reduced the probability of direct pore paths. In contrast, change in PLo from 1.51 to $1.72 \mathrm{Mg} \mathrm{m}^{-3}$ decreasing PLo by $10.5 \%$, demonstrating the greatest ability to discriminate among treatments.
Our results suggest that inclusion of CMT pore characteristics allow a better description of soil structure that can discriminate differences in pore characteristics of soil.

\section{Conclusions}

This study provides insight into the effects of compaction of two aggregate size classes on soil structure parameters through the application of CMT technology at a $9 \mu \mathrm{m}$ scale using a nondestructive and three-dimensional rendering microtomography of a loamy sand soil. The effects of compaction levels on the properties of pore radius, largest average pore volume, number of pores, characteristic coordination number, path length, and tortuosity were investigated. The results provide a picture of how the pore space changes as the porosity decreased with compaction. These results can improve quantification and the ability to model soil structure. This method should aid with the development of tools to better assess soil structure and the measure the benefits of soil management to improve soil quality.

The study approach detected significant differences in certain measured parameters. The study results also show that differences in tortuosity were not clearly detected by the microtomography method used in this study. This could possibly be because of the imaging resolution and image analysis procedures used in the study.

Acknowledgements. We acknowledge the BARD-US research project (grant no. US-3393-03) for the financial support. Appreciation is extended to Brent Lindquist, Srilalitha Yanamanamanda, Thomas Smith, Mark Rivers, and Brian Hedecker for computer software and assistance with data analysis, and Mark A. Haidekker for providing computing resources.

Edited by: J. Vanderborght

\section{References}

Al-Raoush, R. I.: Extraction of physically-realistic pore network properties from three-dimensional synchrotron microtomography images of unconsolidated porous media, $\mathrm{PhD}$ Diss., Louisiana State University, Baton Rouge, LA, p. 173, 2002.

Asseng, S., Alymore, L. A. G., MacFall, J. S., Hopmans, J. W., and Gregory, P. J.: Computer-assisted tomography and magnetic resonance imaging, in: Techniques for studying roots, edited by: Smit, A. L., Bengough, A. G., Engels, C., van Noordwijk, M., Pellerin, S., and van de Geijn, S. C., Springer, Berlin, 343-363, 2000.

Assouline, S.: Modeling soil compaction under uniaxial compression, Soil Sci. Soc. Am. J., 66, 1784-1787, 2002.

Assouline, S.: Rainfall-induced soil surface sealing: a critical review of observations, conceptual models and solutions, Vadose Zone J., 3, 570-591, 2004.

Assouline, S.: Modeling the relationship between soil bulk density and water retention curve, Vadose Zone J., 5, 554-563, $2006 \mathrm{a}$. 
Assouline, S.: Modeling the relationship between soil bulk density and the hydraulic conductivity function, Vadose Zone J., 5, 697705, 2006b.

Assouline, S., Tavares-Filho, J., and Tessier, D.: Effect of compaction on soil physical and hydraulic properties: Experimental results and modeling, Soil Sci. Soc. Am. J., 61, 390-398, 1997.

Beven, K. and Germann, P.: Macropores and water flow in soils, Water Resour. Res., 18, 1311-1325, 1982.

Brussaard, L. and van Faassen, H. G.: Effects of compaction on soil biota and soil biological processes, in: Soil compaction in crop production, edited by: Soane, B. D. and vanOuwerkerk, V., Elsevier Science, Amsterdam, 215-235, 1994.

Carlson, W. D., Rowe, T., Ketcham, R. A., and Colbert, M. W.: Application of high resolution X-ray computed tomography in petrology, meteoritics, and palaeontology, in: Application of Xray Computed Tomography in the Geosciences, edited by: Mess, F., Swennen, R., Van Geet, M., and Jacobs, P., The Geological Society, London, 7-22, UK, 2003.

Coles, M. E., Hazlett, R. D., Spanne, P., Soll, W. E., Muegge, E. L., and Jones, K. W.: Pore level imaging of fluid transport using synchroton X-ray microtomography, Petrol. Sci. Eng., 19, 55-63, 1998.

Cormen, T. H., Leiserson, C. E., and Rivest, R. L.: Introduction to Algoriths, MIT Press, Cambridge, MA, p. 1028, 1990.

Fox, G. A., Malone, R. M., Sabbagh, G. J., and Rojas, K.: Interrelationship of macropores and subsurface drainage for conservative tracer and pesticide transport, J. Environ. Qual., 33, 2281-2289, 2004.

Friedman, S. P. and Robinson, D. A.: Particle shape charaterization using angle of repose measurements for predicting the effective permittivity and electrical conductivity of saturated granular media, Water Resour. Res., 38, 1236, doi:10.1029/2001WR000746, 2002.

Gantzer, C. J. and Anderson, S. H.: Computed tomographic measurement of macroporosity in chisel-disk and no-tillage seedbeds, Soil Till. Res., 64, 101-111, 2002.

Green, T. R., Ahuja, L. R., and Benjamin, J. G.: Advances and challenges in predicting agricultural management effects on soil hydraulic properties, Geoderma, 116, 3-27, 2003.

Gregory, P. J., Hutchison, D. J., Read, D. B., Jenneson, P. M., Gilboy, W. B., and Morton, E. J.: Noninvasive imaging of roots with high resolution X-ray microtomography, Plant Soil, 255, 351-359, 2003.

Ioannidis, M. A. and Chatzis, I.: Network modeling of pore structure and transport properties of porous media, Chem. Engi. Sci., 45, 951-972, 1993.

Ioannidis, M. A. and Chatzis, I.: On the geometry and topology of 3D stochastic porous media, J. Colloid Interf. Sci., 229, 323-334, 2000.

Kim, H. M., Anderson, S. H., Motavalli, P. P., and Gantzer, C. J.: Compaction effects on soil macropore geometry and related parameters for an arable field, Geoderma, 160, 244-251, 2010.

Kinney, J. H. and Nichols, M. C.: X-ray tomographic microscopy (XTM) using synchrotron radiation, Annu. Rev. Mater. Sci., 22, 121-152, 1992.

Knongolo, N. V. and Caron, J.: Pore space organization and plant response in peat substrate: II Dendrathemum morifolium Ramat, Scient. Res. Essay, 1, 93-102, 2006.
Kozaki, T., Suzuki, S., Kozai, N., Sato, S., and Ohashi, H.: Observation of microstructures of compacted bentonite by microfocus X-ray computerized tomography (Micro-CT), J. Nucl. Sci. Technol., 38, 697-699, 2001.

Kumar, S., Anderson, S. H., Bricknell, L. G., and Udawatta, R. P.: Soil hydraulic properties influenced by agroforestry and grass buffers for grazed pasture systems, J. Soil Water Conserv., 63, 224-232, 2008.

Kwiecien, M. J., Macdonald, I. F., and Dullien, F. A. L.: Three dimensional reconstruction of porous media from serial section data, J. Microscopy, 159, 343-359, 1990.

Lee, T. C., Kashyap, R. L., and Chu, C. N.: Building skeleton models via 3-D medial surface/axis thinning algorithms, CGVIP: graph, Model Image Process., 56, 462-478, 1994.

Lindquist, W. B.: 3DMA General Users Manual, SUNY-Stony Brook technical report SUNYSB-AMS-99-20, Stony Brook, NY, p. $47,1999$.

Lindquist, W. B.: Quantitative analysis of three dimensional Xray tomographic images, in: Development in X-ray tomography, edited by: Bonse, U., Proceedings of SPIE 4503, SPIE Bellingham, WA, 103-115, 2002.

Lindquist, W. B. and Venkatarangan, A. B.: Investigating 3D geometry of porous media from high resolution images, Phys. Chem. Earth A, 25, 593-599, 1999.

Lindquist, W. B., Lee, S. M., Coker, D. A., Jones, K. W., and Spanne, P.: Medial axis analysis of three dimensional tomographic images of drill core samples, J. Geophys. Res., 101, 8296-8310, 1996.

Lindquist, W. B., Venkatarangan, A. B., Dunsmuir, J. H., and Wong, T. F.: Pore and throat size distributions measured from synchrotron X-ray tomographic images of Fontainebleau sandstones, J. Geophys. Res., 105, 21508-21528, 2000.

Lindquist, W. B., Lee, S. M., Oh, W., Venkatarangan, A. B., Shin, H., and Prodanovic, M.: 3DMA-Rock A Software Package for Automated Analysis of Rock Pore Structure in 3-D Computed Microtomography Images, Department of Applied Mathematics and Statistics, SUNY at Stony Brook, Stony Brook, NY, available at: http://www.ams.sunysb.edu/ lindquis/3dma/3dma_rock/ 3dma_rock.html (last access: November 2011), 2005.

Macedo, A., Crestana, S., and Vaz, C. M. P.: X-ray microtomography to investigate thin layers of soil clod, Soil Till. Res., 49, 249-253, 1998.

Marsili, A., Servadio, P., Pagliai, M., and Vignozzi, N.: Changes of some physical properties of a clay soil following passage of rubber-metal-tracked tractors, Soil Till. Res., 49, 185-199, 1998.

Mooney, S. J.: Three-dimensional visualization and quantification of soil macroporosity and water flow patterns using computed tomography, Soil Use Manage., 18, 142-151, 2002.

Oh, W. and Lindquist, W. B.: Image thresholding by indicator kriging, IEEE T. Pattern Anal. Mach. Intell., 21, 590-602, 1999.

Or, D., Leij, F. J., Snyder, V., and Ghezzehei, T. A.: Stochastic model of post tillage soil pore space evolution, Water Resour. Res., 36, 1641-1652, 2000.

Pachepsky, Y., Yakovchenko, V., Rabenhorst, M. C., Pooley, C., and Sikora, L. J.: Fractal parameters of pore surfaces as derived from micromorphological data: effect of long-term management practices, Geoderma, 74, 305-319, 1996. 
Perret, J., Prasher, S. O., Kantzas, A., and Langford, C.: Threedimensional quantification of macropore networks in undisturbed soil cores, Soil Sci. Soc. Am. J., 63, 1530-1543, 1999.

Peth, S., Nellesen, J., Fisher, G., Beckman, F., and Horn, R.: Dynamics of soil pore space structure investigated by X-ray microtomography, 19th World Congress of Soil Science, Soil solution for a changing world, 1-6 August 2010, Brisbane, Australia, 1720, 2010.

Pierret, A., Capowiez, Y., Belzunces, L., and Moran, C. J.: 3D reconstruction and quantification of macropores using X-ray computed tomography and image analysis, Geoderma, 106, 247-271, 2002.

Rivers, M. L.: Tutorial introduction to X-ray computed microtomography data processing, http://www-fp.mcs.anl.gov/ xray-cmt/rivers/tutorial.html (last access: December 2011), 1998.

SAS Institute: SAS user's guide, Statistics, version 5, SAS Inst., Cary, NC, p. 1956, 1985.

Seright, R. S., Liang, J., Lindquist, W. B., and Dunsmuir, J. $\mathrm{H}$.: Characterizing disproportionate permeability reduction using synchtron X-ray computed tomography, SPE 71508, Society of Petroleum Engineers Annual Technical Meeting, 3 Sepember3 October 2001, New Orleans, Louisiana, 355-364, 2001.

Shin, H., Lindquist, W. B., Sahagian, D. L., and Song, S. R.: Analysis of sesicular structure of basalts, Comput. Geosci., 31, 473487, 2002.

Shrader, S., Rogasik, H., Onasch, I., and Jégou, D.: Assessment of soil structural differentiation around earthworm burrows by means of X-ray computed tomography and scanning electron microscopy, Geoderma, 137, 378-387, 2007.

Sirjani, A. and Cross, V: On representation of a shape's skeleton, Pattern Recog. Lett., 12, 149-154, 1991.
Soane, B. D. and van Ouwerkerk, C.: Implications of soil compaction in crop production for the quality of the environment, Soil Till. Res., 35, 5-22, 1995.

Thieme, J., Schneider, G., and Knöchel, C.: X-ray tomography of a microhabitat and other soil colloids with sub- $100 \mathrm{~nm}$ resolution, Micron, 34, 339-344, 2003.

Tollner, E. W., Radcliffe, D. E., West, L. T., and Hendrix, P. F.: Predicting hydraulic transport parameters from X-ray CT analysi,. Paper 95-1764, ASAE, St. Joseph, MI, 22 pp., 1995.

Udawatta, R. P., Gantzer, C. J., Anderson, S. H., and Garrett, H. E.: Agroforestry and grass buffer effects on pore characteristics measured by high-resolution X-ray computed tomography, Soil. Sci. Soc. Am. J., 72, 295-304, 2008.

Venkatarangan, A. B.: Geometric and statistical analysis of porous media, PhD Diss., Stat Univ. of New York, Stony Brook, NY, p. 113, 2000.

Whalley, W. R., Dimitru, E., and Dexter, A. R.: Biological effects of soil compaction, Soil Till. Res., 35, 53-68, 1995.

Wildenschild, D., Hopmans, J. W., Vaz, C. M. P., Rivers, M. L., Rikard, D., and Christensen, B. S. B.: Using X-ray computed tomography in hydrology: systems, resolutions, and limitations, J. Hydrol., 267, 285-297, 2002.

Wu, Y. S., van Vliet, L. J., Frijlink, H. W., and van der Voort Maarschalk, K.: The determination of relative path length as a measure for tortuosity in compacts using image analysis, Eur. J. Pharmaceut. Sci., 28, 433-440, 2006.

Young, I. M. and Crawford, J. W.: Interactions and self-organization in the soil-microbe complex, Science, 304, 1634-1637, 2004.

Zhang, X., Leeks, L. K., Bengough, A. G., Crawford, J. W., and Young, I. M.: Determination of soil hydraulic conductivity with the lattice Boltzmann method and soil thin-section technique, J. Hydrol., 306, 59-70, 2005. 